\title{
Megaeventos: \\ a arquitetura do espetáculo \\ e o espetáculo da arquitetura
}

\author{
Ricardo Alexandre Paiva*
}

Resumo Este artigo consiste em uma reflexão teórica e crítica sobre a relação entre a arquitetura e o espetáculo, enfatizando sua relação com os megaeventos desde o advento da modernidade. Assim, parte-se do pressuposto que a arquitetura produz e reproduz o atual processo de espetacularização da cultura por meio da exacerbação da valorização da imagem, suscitados em grande medida pelo caráter midiático dos megaeventos. A relevância do trabalho se sustenta na necessidade de compreender o significado da arquitetura e o papel dos arquitetos no contexto das práticas sociais (econômicas, políticas e simbólicas) e espaciais dos megaeventos na contemporaneidade.

Palavras-chave: megaeventos, arquitetura, espetáculo.

\section{Mega-events: the architecture of the spec- tacle and the spectacle of the architecture}

\begin{abstract}
This paper consists of a theoretical and critical reflection about the relation between architecture and spectacle, emphasizing its relationship with mega-events since the advent of modernity. Thus, it is based on the assumption that architecture produces and reproduces the current process of spectacularization of culture through the exacerbation of the valorization of the image, raised to a great extent by the mediatic character of the mega-events. The relevance of the work is based on the need to understand the meaning of architecture and the role of architects in the context of the social (economic, political and symbolic) and spatial practices of the mega-events in contemporary times.
\end{abstract}

Keywords: words.

\section{Megaeventos: la arquitectura del espectá- culo y el espectáculo de la arquitectura}

\begin{abstract}
Resumen. Este artículo consiste en una reflexión teórica y crítica sobre la relación entre la arquitectura y el espectáculo, enfatizando su relación con los megaeventos desde el advenimiento de la modernidad. Así, se parte del supuesto que la arquitectura produce y reproduce el actual proceso de espectacularización de la cultura por medio de la exacerbación de la valorización de la imagen, suscitados en gran medida por el carácter mediático de los megaeventos. La relevancia del trabajo se sustenta en la necesidad de comprender el significado de la arquitectura y el papel de los arquitectos en el contexto de las prácticas sociales (económicas, políticas y simbólicas) y espaciales de los megaeventos en la contemporaneidad.
\end{abstract}

Palabras clave: megaeventos, arquitectura, espectáculo. 
Nosso tempo, sem dúvida... prefere a imagem à coisa, a cópia ao original, a representação à realidade, a aparência ao ser... (Feuerbach apud Debord, 1997, p. 13)

D

e origem latina spectaculum, a palavra espetáculo significa chamar a atenção pública, atrair e despertar a curiosidade visual. No contexto da gênese do termo, o espetáculo se relacionava às atividades cênicas (teatro e dança) e aos jogos antigos, constituindo, assim, eventos sociais de significativa visibilidade coletiva. Esta ampla audiência justificava a derivação do termo espetáculo de spectáre, associado ao ato de observar com atenção, assistir, contemplar, sendo, os espetáculos, portanto, práticas direcionadas a um grande número de expectadores. O substantivo espetáculo é, ainda, sinônimo de evento público e pressupõe atividades culturais magníficas que se manifestam em um acontecimento incomum, inesperado e icônico, segundo o Grande dicionário etimológico-prosódico da língua portuguesa (Bueno, 1961), algo digno de ser admirado e visto.

Sendo assim, desde sua origem, espetáculo e evento são dois conceitos intricados, que apresentam expressivo conteúdo espacial, uma vez que, historicamente, os espaços produzidos (arquitetura e cidade) pelo poder possuem a dupla função de palco e cenário de realização desses eventos magnificentes, ao mesmo tempo que, como objetos, conformam, expressam e simbolizam eles mesmos o caráter extraordinário e espetacular pretendido.

A arquitetura do espetáculo e o espetáculo da arquitetura em sua relação com os megaeventos constituem, assim, o tema central a ser discutido neste artigo. Para tanto, resgatam-se as origens históricas desta relação, enfatizando o papel da forma na cultura arquitetônica contemporânea, sobretudo pela mercantilização de sua imagem como instrumento de valorização dos megaeventos e, consequentemente, a função desempenhada pela arquitetura no processo de reprodução do capitalismo. Destacam-se, ainda, exemplos emblemáticos da relação arquitetura e espetáculo.

\section{O espaço do espetáculo desde a Modernidade}

Desde tempos remotos, o espetáculo contido nos eventos tem sido utilizado como instrumento de controle social e mobilização das massas na manutenção da hegemonia econômica e política das elites. A construção de artefatos urbanos e arquitetônicos espetaculares, que cumpriram papel destacado no acolhimento de eventos civis e

* Ricardo Alexandre Paiva é Arquiteto e Urbanista, professor da Universidade Federal do Ceará, ORCID $<$ https://orcid.org/0000-00020332-097X>. religiosos, artísticos e esportivos, serviu também como meio de expressão cultural de valores simbólicos e ideológicos, condizentes com o contexto histórico e geográfico de sua inserção, criando autênticos ícones urbanos.

É remoto o papel da intervenção urbana e da arquitetura na criação de ícones que sintetizaram, no ambiente construído e em suas representações simbólicas, 
aspirações culturais e ideológicas das mais diversas (religiosas, políticas, étnicas, econômicas) (Paiva, 2016, p. 292).

Em vários momentos da história, os eventos espetaculares foram utilizados como recurso pelos detentores do poder para legitimar seus interesses e domínios econômicos, políticos e cultural-ideológicos, "apropriando-se do entretenimento, da arte e da festividade para distrair, apaziguar e controlar as massas" (Broudehoux, 2011, p. 40).

Desde a Revolução Industrial, com seus desdobramentos na produção de bens e serviços na gênese do capitalismo, o espetáculo adquire uma complexidade à altura dos dilemas impostos pela modernidade, muito embora conserve seu potencial de alienação social verificado em grande medida desde a Antiguidade.

A produção de mercadorias e a reprodução do capitalismo são tributárias da necessidade de controle social por intermédio da posse da força de trabalho por partes das elites políticas e econômicas, exacerbando as diferenças de classes e repercutindo na distinção das práticas culturais de ricos e pobres, com desdobramentos espaciais:

Os ambientes privados e públicos - até agora sempre ligados e misturados - na cidade burguesa se tornam contrapostos entre si: (...) também os espetáculos e as cerimônias coletivas adquirem caráter e distinção em pequenos ambientes fechados - os teatros, os "salóes" - que não têm qualquer proporção com o tamanho da cidade (o novo Teatro da Opera de Paris tem pouco mais de 2000 lugares, ao passo que a cidade tem dois milhões de habitantes; comparam com a antiga Atenas, onde quase toda a população podia entrar no Teatro de Dionísio) (Benévolo, 1997, p. 595).

A segunda metade do século XIX testemunha a efervescência de práticas culturais espetaculares, incrementadas pelo avanço da urbanização, tanto no sentido de aumento e concentração da população em um espaço restrito, quanto relacionado "à existência e à difusão de um sistema cultural especifico, a cultura urbana" (Castells, 2009, p. 46).

Harvey, ao se referir a Paris como capital da modernidade, reconhece que:

O espetáculo, mesmo aquele da própria cidade, sempre foi fundamental para a vida urbana, e por muito tempo seus aspectos políticos desempenharam um papel importante na construção da legitimidade e controle social (Harvey, 2015, p. 283).

A centralidade mundial exercida por Paris no século XIX pode ser comparada ao papel que Roma cumpriu na Antiguidade. Depois de 1850, sob o regime do Segundo Império de Napoleão III, sobrinho de Napoleão Bonaparte, com a realização de diversas cerimônias, casamentos imperiais, funerais e visitas de autoridades internacionais, além de desfiles militares, "tudo isso proporcionava ocasiões para mobilizar espetáculos de apoio ao poder imperial" (Harvey, 2015, p. 282). Colaboraram como cenário e demonstração do espetáculo de Paris as intervenções monumentais promovidas por Haussmann, visíveis nos bulevares, nos focos perspectivos assinalados por importantes edifícios, símbolos do novo regime.

Assim, o espetáculo é um meio de reprodução do capitalismo, sendo os bulevares de Paris um exemplo acabado, uma vez que eram espaços que, além de demonstrarem o poder, 
Figura 1: Palácio de Cristal (1851), de Joseph Paxton, em Londres. Fonte: Domínio Público <https://en.wikipedia.org/ wiki/The_Crystal_Palace\#/media/ File:The_Crystal_Palace_in_Hyde_. Park_for_Grand_International_ Exhibition_of_1851.jpg>. permitiam a circulação de mercadorias, pessoas e capital. "Os bulevares tornaram-se espaços públicos onde o fetiche da mercadoria reinava soberano" (Harvey, 2015, p. 290).

As Exposições Universais e os Jogos Olímpicos modernos são os eventos mais importantes surgidos na segunda metade do século XIX, que demonstram a íntima relação entre o espetáculo, a intervenção urbana e a produção da arquitetura, todos conjugados, social e espacialmente, com o propósito econômico, político e simbólico de arrebatar a sociedade moderna, homogeneizando formas de produção e consumo cultural.

Não se pretende aprofundar aqui as motivações sociais e as expressões urbanas e arquitetônicas das grandes exposições, mas cabe destacar que elas colaboraram para o processo de fetichização da mercadoria, uma vez que eram lugares/espaços onde "a fantasmagoria da cultura capitalista atingiu seu desdobramento mais radiante" (Benjamim, 1973, p. 166-167), em torno também da diversão e do entretenimento, colaborando ainda para a consolidação do capitalismo, uma vez que "as exposições atraíam multidões das províncias e do exterior, estimulando o consumo. E a montagem de todos esses espetáculos exigia técnica, mão de obra, mercadorias e dinheiro. Por isso, houve um considerável estímulo à economia" (Harvey, 2015, p. 288).

As intervenções urbanas e arquitetônicas suscitadas pelas Exposições demonstram nitidamente que o espetáculo tem como protagonistas os produtos industriais, incluindo a própria arquitetura dos pavilhões e as infraestruturas, agregando ao caráter espetacular, anteriormente associado a regimes e pessoas (religiosos, políticos, reis, ídolos), a produção, a distribuição e o consumo de bens materiais.

Neste cenário, destaca-se: o Palácio de Cristal (Figura 1) implantado no Hyde Park em Londres, celebrando a Grande Exposição Internacional de 1851, que inaugura a era dos grandes eventos da modernidade e a sequência de cinco Exposições Internacionais

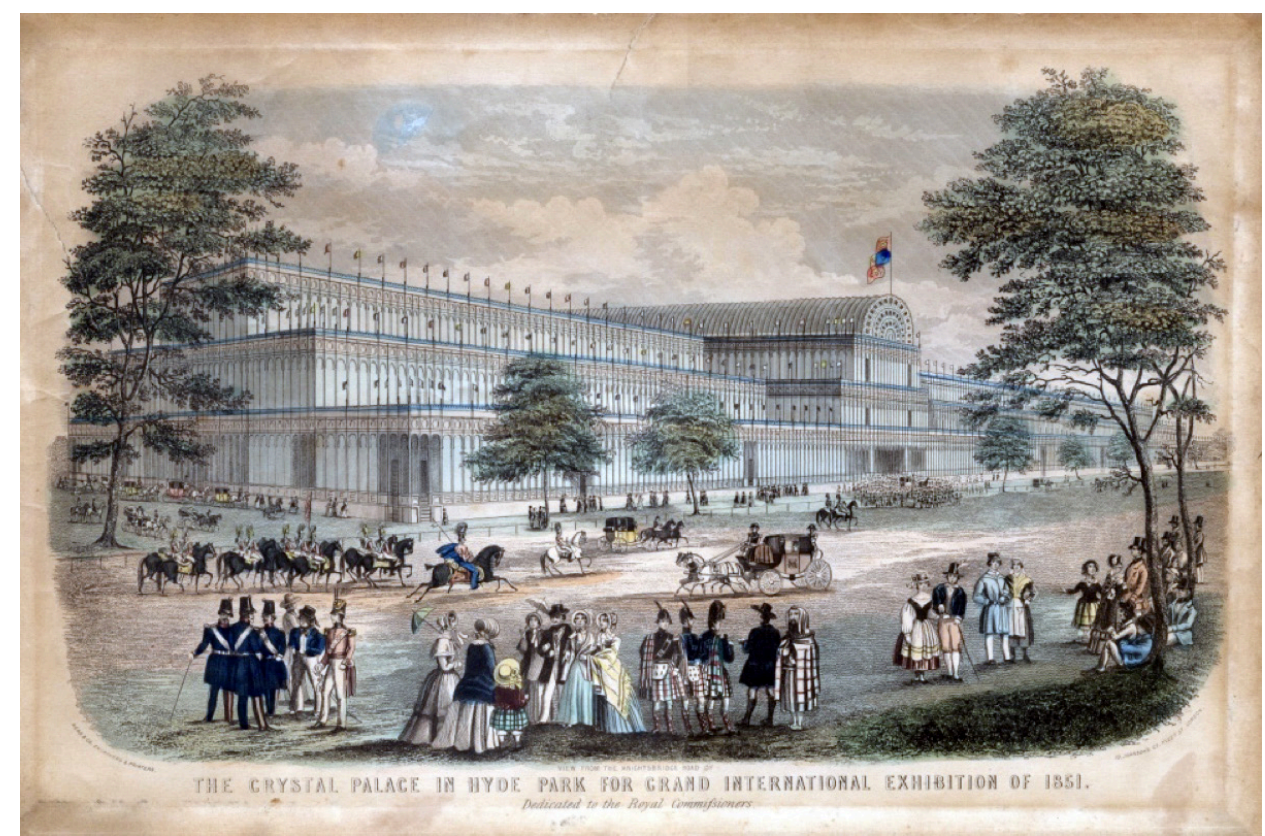




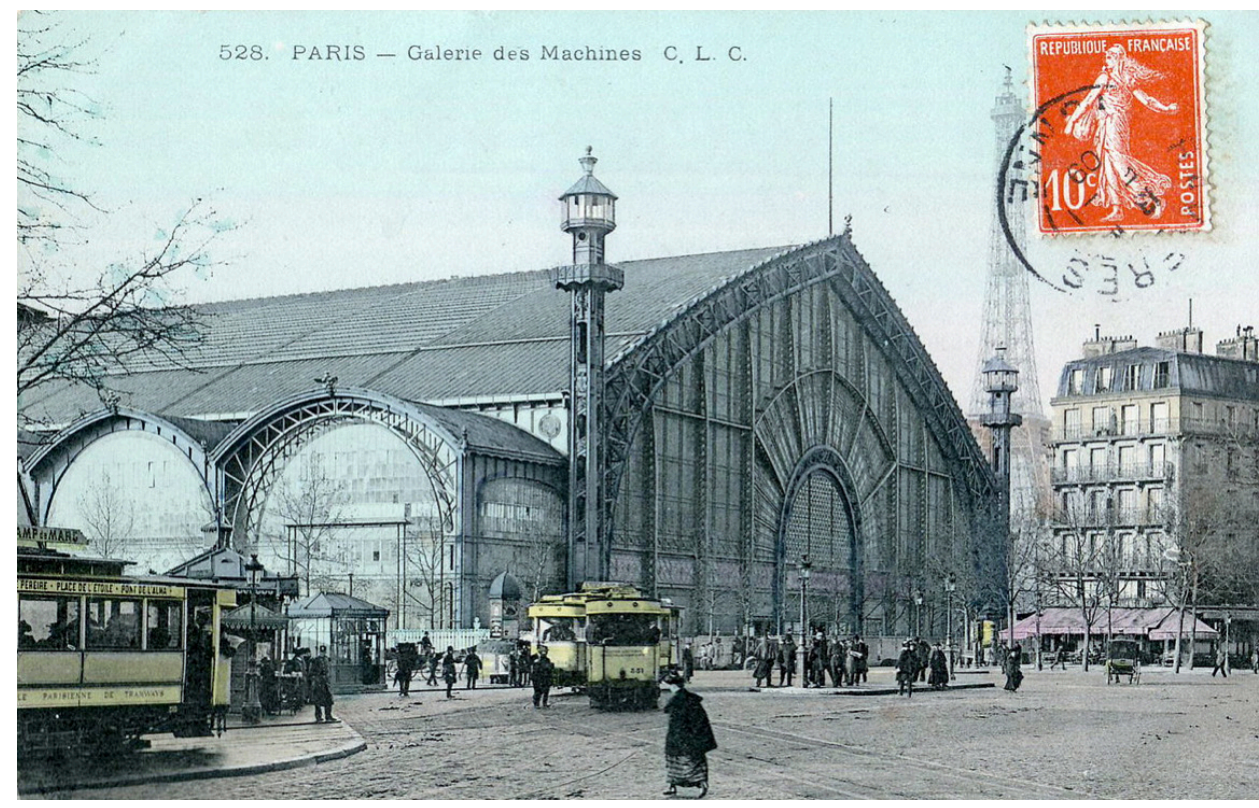

Figura 2: Galeria das Máquinas (1889), do arquiteto Ferdinand Dutert e do engenheiro Victor Contamin, em Paris. Edifício demolido em 1910. Fonte: Domínio Público <https://en.wikipedia. org/wiki/Exposition_Universelle_ (1889)\#/media/File:CLC_528_-PARIS_-_Galerie_des_Machines. jpg $>$. em Paris, de 1855 a 1900, tendo como os maiores ícones o Pavilhão (Galeria) das Máquinas (Figura 2) e a Torre Eiffel na Exposição Universal de Paris de 1889.

Reforçam esta ode à mercadoria as lojas de departamento surgidas no século XIX, nas quais as vitrines se converteram em um cenário "espetaculoso" e atraente no cotidiano dos grandes centros urbanos, além dos cafés, dos novos meios de transporte e das práticas de lazer nos parques, valorizando os espaços públicos.

Conquanto a industrialização proporcionasse a diminuição do valor de alguns bens e multiplicasse as possibilidades de aquisição de mercadorias, ela acirrava as diferenças de classe. A compra e o consumo se converteram em um espetáculo que os menos favorecidos assistiam e, ao mesmo tempo, ansiavam participar ativamente.

Malgrado o resgate de alguns valores simbólicos dos jogos olímpicos antigos, as Olimpíadas modernas possuem um caráter totalmente laico e colocam em evidência o esporte moderno, que também é fruto da modernidade, uma vez que pressupõe competitividade, rendimento, regras, eficácia e progresso. "Sem contar outra diferença fundamental: o nível de violência, que nos esportes modernos é sensivelmente mais tênue do que nos jogos gregos" (De Lima; Martins; Capraro, 2009).

As Olimpíadas modernas conservam, sobretudo na segunda metade do século XX, quando passam a acontecer com maior regularidade após a instabilidade sofrida no contexto das duas Grandes Guerras Mundiais, a necessidade de intervenções urbanas e instalações esportivas específicas para sua consecução, além do caráter simbólico associado às paixões e emoções desencadeadas pelo esporte e seus usos econômicos, políticos e ideológicos. 
Trata-se de um novo espetáculo esportivo, com seus rituais renovados (a tocha, o hino, o símbolo olímpico, o recorde), exigindo instalações adequadas aos esportes que se diversificaram e se internacionalizaram. Os estádios desde então são palco do fair play e abrigam atividades de atletismo e jogos coletivos, sendo o futebol o mais popular, disseminando-se exponencialmente como um grande espetáculo mundial.

Ao longo do século $X X$, as modalidades esportivas se ampliam, sofisticam e se profissionalizam, constituindo importante nicho de desenvolvimento econômico, arena de disputas políticas entre Estados e nações, representação de significados culturais, étnicos, religiosos e de gênero.

Em síntese, desde a Antiguidade, o espetáculo e a arquitetura a ele associado tiveram como uma das funções principais intensificar o controle social por meio da alienação para a manutenção dos poderes hegemônicos. Na atualidade, este processo de alienação é mediado pelo consumo de mercadorias, constituindo uma estratégia dos detentores do capital. Conforme será visto adiante, esta fetichização da mercadoria se sofistica na medida em que o espetáculo passa a ser mediado pela imagem.

\section{A cultura contemporânea do espetáculo}

Desde o século XIX, a noção de espetáculo se identifica com o conceito de alienação de Marx, em que o alheamento social é resultado do fetiche da mercadoria, ou seja, um processo de primazia das mercadorias em relação aos indivíduos, que são capturados pela aquisição e pelo consumo de objetos e experiências das mais diversificadas.

Benjamin precocemente anunciava que a estética estava a serviço de dissimular uma estratégia de poder, de tornar aceitável e fascinante, por meio do espetáculo, uma atitude política "indigesta" (Broudehoux, 2011), ao se referir à estetização da política pelo fascismo, embora isto remonte à Antiguidade, como já assinalado. Desde a década de 1960, com o surgimento de vários movimentos que indicavam mudanças culturais significativas no âmbito da transição da modernidade para a pós-modernidade, a noção de espetáculo discutida por Guy Debord superava sua associação exclusivamente aos regimes totalitários e como uma manifestação do capital, incluindo agora o grande protagonismo assumido pela imagem, uma vez que não somente o produto, mas sua imagem, passaram a circular como mercadorias, pois "o espetáculo é o capital em tal grau de acumulação que se torna imagem" (Debord, 1997, p. 25), protagonizando a alienação, pois "o espetáculo é o momento em que a mercadoria ocupou totalmente a vida social" (Debord, 1997, p. 30).

O que estamos presenciando é uma manifestação mais avançada do fetichismo da mercadoria, pois não se trata apenas de separação entre produto e produtor, mas da separação entre o produto real e a sua imagem como produto imaginário - que passa a circular e valorizar-se com certa autonomia (Arantes, 2012, p. 116).

Llosa (2013) denuncia com pessimismo que o fetichismo da mercadoria no atual estágio da sociedade capitalista pós-industrial passou a ser o interesse e a preocupação central na vida dos consumidores, em detrimento de assuntos de ordem cultural (alta cultura), intelectual e política. 
A aquisição obsessiva de produtos manufaturados, que mantenham ativa e crescente a fabricação de mercadorias, produz o fenômeno da "reificação" ou "coisificação do indivíduo", entregue ao consumo sistemático de objetos, muitas vezes inúteis e supérfluos, que as modas e publicidade vão the impondo, esvaziando sua vida interior de preocupações sociais, espirituais ou simplesmente humanas, isolando-o e destruindo a consciência que ele tenha dos outros, de sua classe e de si mesmo; como conseqüência, por exemplo, o proletário "desproletarizado" pela alienação deixa de ser um perigo - e até um antagonista - para a classe dominante (Llosa, 2013, p. 20-21).

As práticas culturais contemporâneas, representadas majoritariamente pela cultura de massa, combinadas e confundidas com o entretenimento, constituem expressões das ações individuais e particulares de consumo de bens tangíveis e intangíveis, "sinalizando uma tendência crescente de mercantilização da cultura no contexto da sociedade do espetáculo" (Paiva, 2016, p. 301). É importante destacar que, para as minorias (associadas aos movimentos de contracultura), as diversas formas de expressão cultural foram uma conquista, sinalizando o aspecto homogêneo do consumo e heterogêneo das formas e das mercadorias, contrapondo-se às generalizações da tradição moderna.

Para Debord (1997), o estágio espetacular da sociedade modernizada tem como característica a combinação de alguns aspectos, sendo um deles "a incessante renovação tecnológica". Os meios de comunicação, desde o advento do cinema, da televisão e mais recentemente do computador e dos smartphones, demonstram que a tela potencializou a audiência do espetáculo, facilitando, consequentemente, a valorização e a circulação de imagens e favorecendo a penetração do capital em escala global.

Assim, a produção de imagens fica subordinada à "lógica cultural do capitalismo tardio" (Jameson, 1996) e, por isso mesmo, "a imagem tem sido criticada, porque ela presumidamente simplifica, mascara e manipula a verdade" (Ursprung, 2005, p. 75).

A cultura contemporânea do espetáculo coloca em evidência e supervaloriza a indústria do entretenimento, regida pelo mercado que superestima o valor de troca e o hedonismo das práticas culturais, pois "cultura é diversão, e o que não é divertido não é cultura" (Llosa, 2013, p. 27).

As manifestações culturais e as competições esportivas se inserem no rol de (mega) eventos, que se transformaram em um "grande negócio" na atualidade, tendo como suporte para obtenção de seus objetivos o uso da imagem como estratégia simbólica. Neste contexto, o esporte é um dos grandes protagonistas do entretenimento, sendo produzido e consumido como um espetáculo, proporcionando um processo de acumulação desde uma base não produtiva.

Valores arquétipos do espetáculo persistem no futebol, o esporte mais popular do mundo, que entusiasma as massas, despertando o interesse e os instintos dos espectadores e, por isso mesmo, desencadeando diversas dinâmicas econômicas.

Mas, em nossos dias, as grandes partidas de futebol, assim como outrora os circos romanos, servem sobretudo como pretexto e liberação do irracional, como regressão do indivíduo à condição de partícipe da tribo, como momento gregário em que, 
amparado no anonimato aconchegante da arquibancada, o espectador dá vazão a seus instintos agressivos de rejeição ao outro, conquista e aniquilação simbólica (e ás vezes até real) do adversário (Llosa, 2013, p. 35).

Em síntese, a cultura contemporânea do espetáculo se funda no conceito de espetáculo integrado proposto por Debord (1997), que consiste na síntese do espetáculo concentrado, relacionado ao poder político (do Estado, de regimes autoritários) e do espetáculo difuso, relacionado ao poder econômico e ao culto à mercadoria. Para Broudehoux (2011), o espetáculo integrado surge a partir do final da década de 1960 como uma expressão do capitalismo global e da sociedade de consumo.

\section{Megaeventos, arquitetura e espetáculo}

Os megaeventos contemporâneos (sobretudo os esportivos), embora aconteçam de forma pontual no tempo e no espaço como algo efêmero e fugaz, têm a condição de "megaevento" justificada por seu caráter multidimensional, que se traduzem em uma variedade de práticas, ações e dimensões econômicas, políticas e simbólicas que transcendem a escala local e apontam para um elevado nível de articulação entre os lugares e os agentes envolvidos globalmente e se traduzem em uma complicada trama de interesses, conexões e conflitos (Paiva, 2016).

A dimensão econômica associada aos megaeventos assumiu uma complexidade à altura da visibilidade midiática do evento em questão, proporcionada pelos avanços da tecnologia, tornando-se ele mesmo um (mega) evento econômico. Embora as práticas econômicas relacionadas aos megaeventos confirmem a ênfase do setor terciário em detrimento do secundário no contexto atual da desindustrialização e do pós-fordismo, eles desencadeiam toda a economia do lugar-sede, atingindo diretamente um conjunto de setores importantes para viabilizar sua realização, diluindo-se em suas cadeias produtivas e alcançando indiretamente outros setores e campos variados (Turolla, 2009), impactando a produção, a distribuição e o consumo de bens materiais e serviços.

A dimensão política no contexto dos megaeventos envolve as práticas de poder que se manifestam nas relações de dominação em escalas global e local, abrangendo organizações e empresas transnacionais (FIFA e COI, por exemplo), as diversas esferas dos Estados nacionais e a sociedade (turistas, visitantes, residentes etc.). Nesse contexto, a realização de um megaevento passa a ser um nicho privilegiado para a atuação das iniciativas privadas, representando, assim, um sintoma do neoliberalismo.

A dimensão simbólica (cultural-ideológica) dos megaeventos se relaciona em grande parte aos seus efeitos intangíveis, muito embora não esteja apartada dos desígnios econômicos e políticos, no qual reagem de forma dialética. A articulação entre as dimensões simbólica e econômica pode ser comprovada com base na noção de "economia simbólica", que constitui uma maneira de desencadear desenvolvimento desde uma "base inteiramente cultural, isto é, não produtiva" (Zukin, 2003, p. 12). O caráter simbólico dos megaeventos reforça a hegemonia política dos agentes promotores públicos e privados.

Lastreado na dimensão econômica, política e simbólica dos megaeventos, fica patente o papel dos megaeventos no processo de produtividade e competitividade urbanas, na 
medida em que orienta a produção e o consumo do espaço urbano e arquitetônico dos lugares que o sediam, valendo-se do espetáculo (conteúdo e forma) como estratégia de reprodução do capital em escala global, assevera Arantes (2011, p. 74): "tais eventos, ao criar excepcionalidades transitórias (...) deixam no seu rastro localizações diferenciadas no espaço e no tempo, distinções graças às quais se abrem então novas fronteiras de acumulação".

A produção e consumo dos espetáculos urbanos possuem como nicho privilegiado os megaeventos.

O espetáculo é tão essencial para a nova economia urbana que um dos meios mais eficazes para intensificar a imagem mundial de uma cidade é sediar eventos globais, tais como mostras, conferências e grandes competições esportivas internacionais (Broudehoux, 2011, p. 42).

A arquitetura e o espaço urbano espetaculares não são somente o repositório das ações, práticas e eventos de exibição do poder do Estado, das classes capitalistas transnacionais (Sklair, 2006), e do capital; elas são o espetáculo em si, constituindo a expressão estética usada como mecanismo de obtenção de vantagens econômicas.

A arquitetura é um dos principais campos de expressão da cultura do espetáculo no contexto do capitalismo contemporâneo, uma vez que tende a um processo crescente de comodificação, que superestima a imagem. As tendências pós-modernas na arquitetura, fundadas na crítica ao modernismo, apontavam desde sua origem para a valorização do caráter imagético dos edifícios, estabelecendo novas linguagens de comunicação com o público, empregando desde o recurso ao historicismo e à intervenção no patrimônio edificado, passando pela incorporação da estética do consumo, das marcas, da propaganda e da pop art, até a "escandalização" da subjetividade e da abstração com a concepção de formas inéditas e icônicas, contribuindo para qualificar a arquitetura como mercadoria altamente valorizada e estimada na atualidade.

Assim como em outras expressões da cultura, verifica-se na arquitetura um processo de fetichização da mercadoria por meio de sua imagem, expressa em sua aparência superficial, induzindo a criação de formas espetaculares e se valendo da "renda da forma" como um ativo econômico, ou seja, "a utilização da arquitetura para a obtenção de ganhos monopolistas derivados da atração proporcionada por suas formas únicas e impactantes" (Arantes, 2012, p. 119). Arantes (2012) acrescenta que esta autonomização da imagem gera valor de troca independentemente da produção e do trabalho envolvidos no projeto e na construção, ou seja, o lucro advém da circulação da imagem.

Diante da diversidade de expressões da arquitetura contemporânea, verifica-se como ponto de interseção uma inclinação formalista, com a invenção de formas pretensiosas conscientemente direcionadas para o espetáculo, a fama e o alcance global.

Pensada como algo em si, confrontada com o espaço da existência, essa arquitetura tornou-se formalista, perdeu a noção da justa medida, da proporção e da harmonia, confundindo gigantismo com monumentalidade e objetivou unicamente a grife, 0 exótico, o diferente, o arrojado. Sem dúvida, uma arquitetura imagética em evidente descompasso com a construção do lugar (Castelo, 2013, p. 51). 
Monnier (2009) formula a hipótese de que os edifícios são instrumentos do evento. Primeiro, porque o lugar ou a arquitetura constitui o pano de fundo do evento histórico, que por vezes dá nome ao próprio acontecimento de uma criação cultural; segundo, porque ele pode ser considerado um episódio na história das formas arquitetônicas; e, finalmente, porque o edifício pode ser o instrumento de um evento cultural (ou esportivo), incluindo tanto os monumentos históricos adaptados à produção de espetáculos quanto às edificações cujo programa é relacionado aos eventos.

Nesta categoria, estão incluídos os edifícios que abrigam vários tipos de espetáculos culturais (teatros, salas de concerto) e, evidentemente, as competições esportivas (arenas, estádios, parques e equipamentos olímpicos etc.).

Se admitirmos que hoje a indústria do espetáculo, que se tornou indústria do entretenimento, transforma o espectador em consumidor de cultura e que a necessidade de renovação dos produtos impõe a renovação do evento-chamariz, o edifício ad hoc para cada um desses lugares de produção da indústria do entretenimento está destinado a ser o instrumento do evento: um evento que deve impor-se no espaço social, face à concorrência dos instrumentos tecnológicos do consumo cultural em domicílio (Monnier, 2009, p. 12).

Para o megaevento, a produção de uma arquitetura espetacular torna-se prioridade, pois, embora os edifícios tenham sido historicamente um meio de representação simbólica e suporte de informação cultural, atualmente "o edifício pode tornar-se engrenagem principal de uma máquina de divertir através de eventos" (Monnier, 2009, p. 16).

O edifício-evento sintetiza o espetáculo como algo uno, pois não se trata de uma dualidade entre o evento e a arquitetura, mas uma dialética, qual seja, a arquitetura do espetáculo e o espetáculo da arquitetura.

A essência da arquitetura do espetáculo produzida para o megaevento é seu caráter hedonista, como revela a própria origem da palavra, proveniente do grego hedonikos, com o sentido de prazeroso. Sendo assim, recorre-se a artifícios espaciais, formais, estéticos e tecnológicos para estimular o prazer proporcionado pelo consumo da experiência singular, excepcional e extraordinária que o edifício-evento suscita.

Esta índole hedônica se manifesta esteticamente por intermédio de uma valorização da vocação simbólica da forma, que se traduz em um novo tipo de ornamento, diferente daquele historicamente vinculado ao vocabulário clássico (e combatido por Adolf Loos), associado agora à subjetividade do arquiteto em busca de uma imagem que desperte interesse e atenção do público, ou seja, se transforme em um espetáculo. Para tanto, se recorre ao uso de novas tecnologias digitais e materiais, geometrias complexas e não euclidianas, abstrações e/ou figurações que traduzam uma forma superficial, mas sedutora, que induzam ao clímax da experiência sensorial, que estimule e excite os sentidos.

Este hedonismo está presente tanto na maneira como os arquitetos contemporâneos (starchitects com uma assinatura de grife) concebem, desenham e materializam estes edifícios fantásticos, quanto na recepção, interpretação e fruição dos usuários, que desfrutam presencial ou virtualmente destas imagens midiáticas. Esta atitude hedônica 
se aproxima dos argumentos de Jameson (1996) ao considerar que a cultura do pósmodernismo valoriza a euforia e o simulacro.

Como desdobramento, o espetáculo da arquitetura por meio do processo de reificação da sua imagem induz ao transe e incide no processo de alienação das práticas de consumo cultural, entretenimento e lazer.

Para Neil Leach (apud Broudehoux, 2011), a fetichização da imagem da arquitetura como mercadoria restringiu o discurso arquitetônico no âmbito do estético em detrimento do político, ou seja, a disseminação da arquitetura espetacular e de sua imagem tem efeito anestésico, que reduz a consciência social e política. Significa admitir que o caráter espetacular da arquitetura estaria a serviço do processo de alienação em face de sua comodificação.

Esta arquitetura espetacular é uma exceção na produção arquitetônica contemporânea e não se restringe aos programas associados aos megaeventos esportivos (Copa do Mundo de Futebol e Olimpíadas), que "têm sido também um campo por excelência de produção de ícones urbanos e arquitetônicos, transformando a arquitetura em si mesma um espetáculo" (Paiva, 2016, p. 311), mas está presente em projetos e obras de centros culturais, museus, edifícios culturais (teatros, salas de concerto), hotéis, flagship stores, entre outros.

A aura que adquirem alguns edifícios culturais ou esportivos, ou mesmo monumentos reabilitados e ressemantizados, os qualificam positivamente para continuar sendo palco dos espetáculos que envolvem os eventos na atualidade. Isto significa que seu caráter simbólico, presente em sua condição de ícone, histórico ou inventado, oculte ou tenha primazia sobre atributos historicamente essenciais para a arquitetura, como a interface com o entorno, o conforto, a funcionalidade, a tectônica, por exemplo, ratificando que, na arquitetura do espetáculo, o valor de signo subjaz o valor de uso.

Verifica-se ainda, na arquitetura do espetáculo, que a complexidade da forma como uma categoria estrutural, relacionada aos conteúdos sociais, elementos consistentes, materiais e sólidos, se contrapõe ao caráter icônico, transparente, virtual e imaterial associados à imagem, "simples documentos visuais de reprodução e consumo imediato" (Montaner, 2002, p. 14).

Embora os edifícios projetados para fins de apresentação cultural se alinhem ao conceito de arquitetura do espetáculo proposto, como teatros, salas de concertos e afins, nota-se que os eventos a ele associados, embora de grande audiência, não possuem a repercussão dos megaeventos esportivos. O recurso às formas espetaculares é evidente, como no Walt Disney Concert Hall (2003), de Frank Gehry, em Los Angeles (Figura 3); na Casa da Música (2005), de Rem Koolhaas, no Porto, em Portugal (Figura 4); no Grande Teatro Nacional (2007) em Pequim, do arquiteto francês Paul Andreu, construído no contexto das grandes obras para as Olimpíadas de 2008 na China; na Cidade das Artes (2013), de Christian de Portzamparc, no Rio de Janeiro (Figura 5); e na Filarmônica de Paris, de Jean Nouvel (2015) (Figura 6), só para citar alguns.

Os edifícios construídos para abrigar os megaeventos esportivos potencializam o caráter espetacular da arquitetura, pois reúnem três expressões dos ícones (Sklair, 2010): 

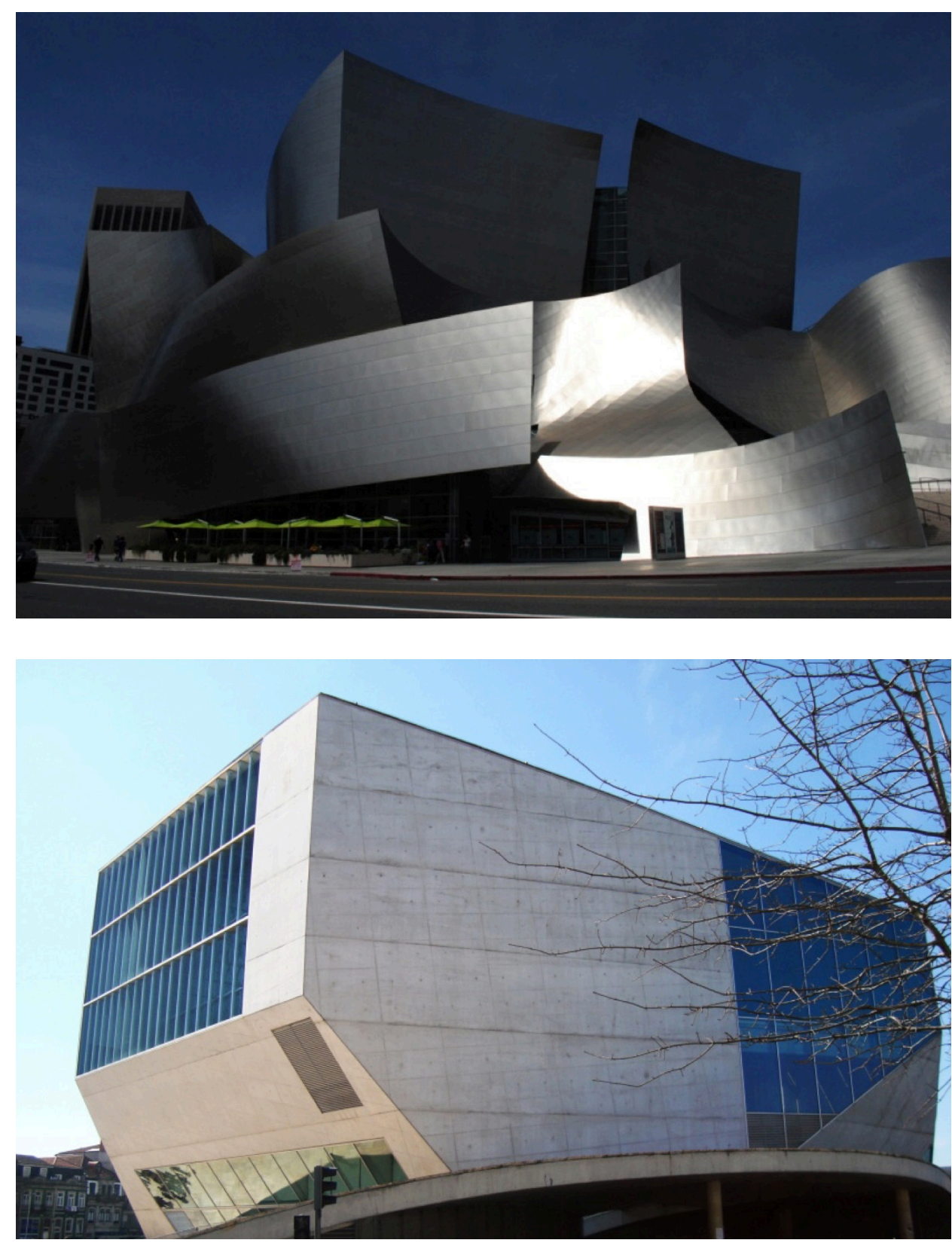

Figura 3 (topo): Walt Disney Concert Hall (2003), de Frank Gehry, em Los Angeles. Fonte: arquivos de Daniel Marques.

Figura 4 (centro): Casa da Música (2005), de Rem Koolhaas, no Porto (Portugal). Fonte: acervo Ricardo Paiva.

Figura 5: Cidade das Artes (2013), de Christian de Portzamparc, no Rio de Janeiro. Fonte: arquivos de Geise Pasquotto.

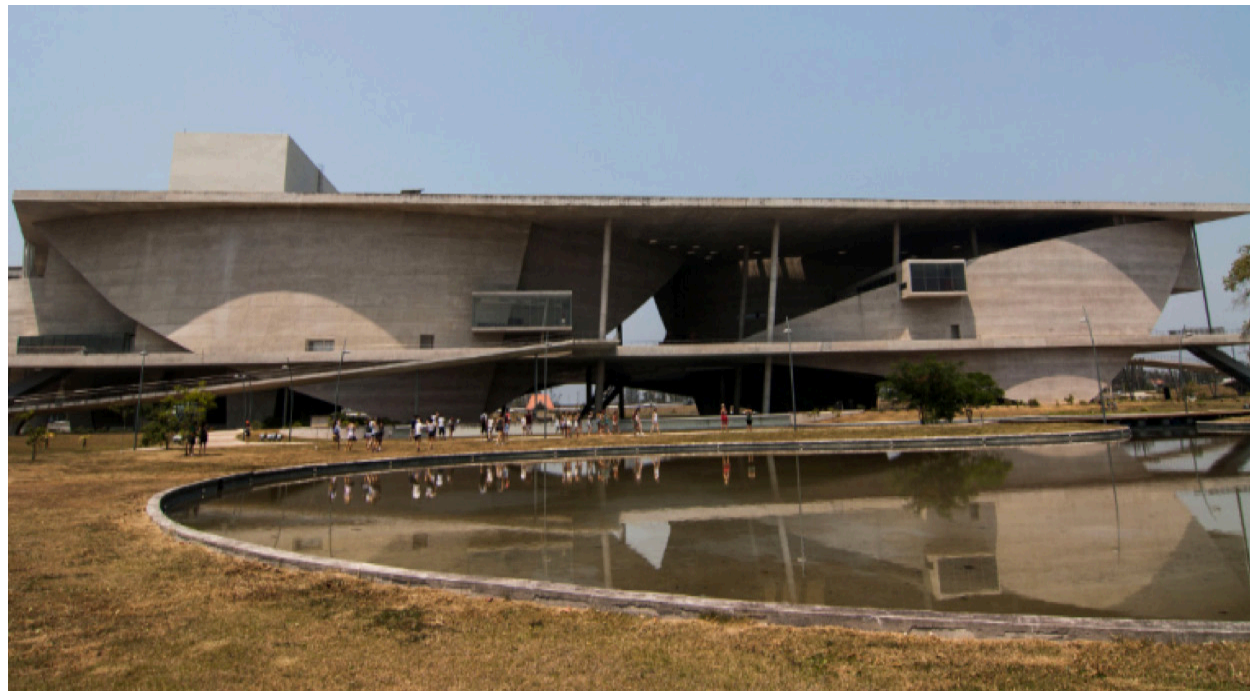




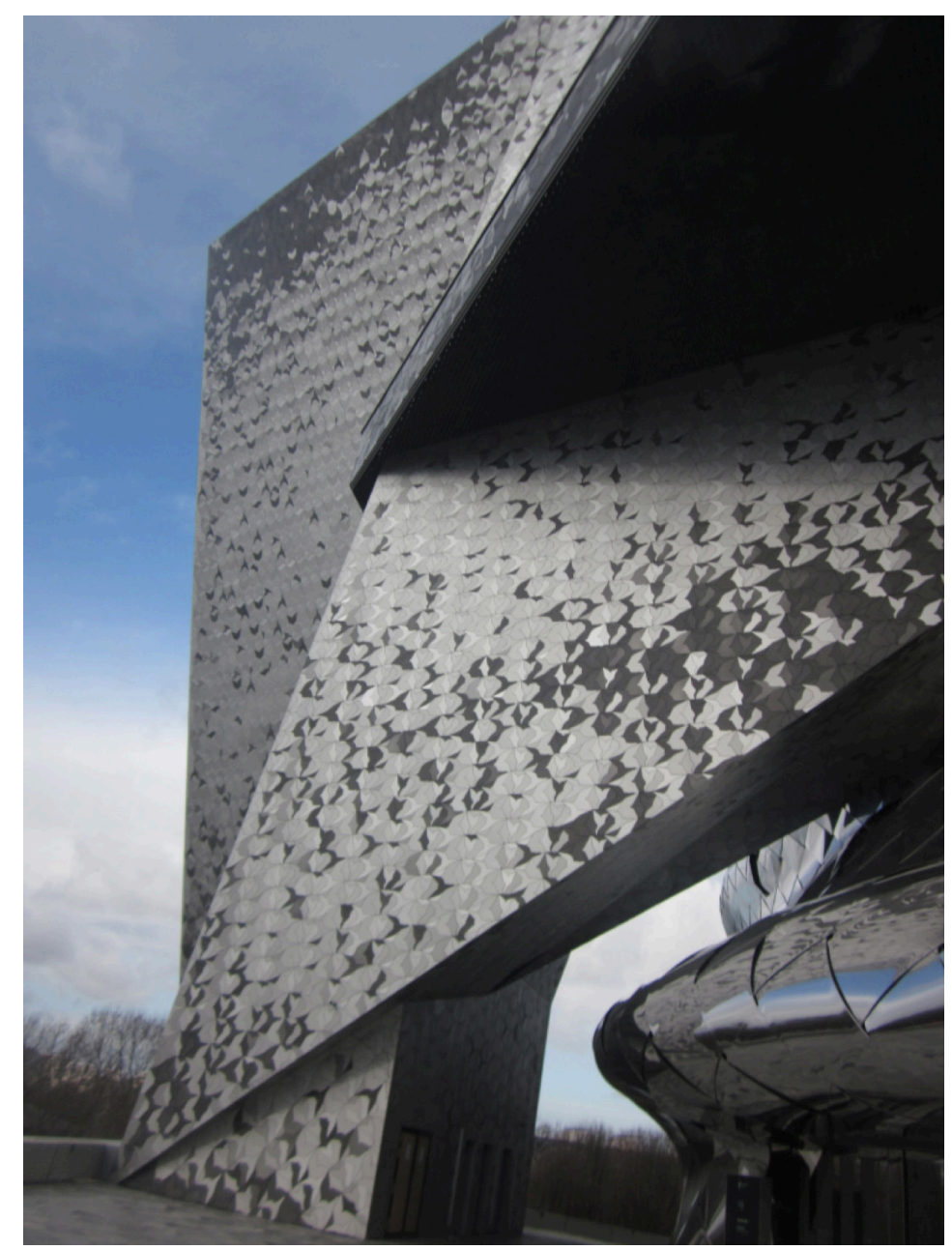

Figura 6: Filarmônica de Paris, de Jean Nouvel (2015). Fonte: arquivos de Beatriz Diógenes. eventos (Olimpíadas e Copa do Mundo de Futebol), pessoas (esportistas, artistas, autoridades) e objetos (a cidade e a arquitetura). Estes objetos arquitetônicos são principalmente as arenas e as instalações para os esportes olímpicos.

As arenas, denominação atual para os estádios de futebol e olímpicos, constituem uma tipologia importante para a experimentação da arquitetura espetacular demandada pelos megaeventos. Conforme as exigências da Federação Internacional de Futebol (Fifa) e do Comitê Olímpico Internacional (COI), elas constituem estruturas arquitetônicas apropriadas para abrigar não só o espetáculo dos jogos, mas também uma variedade de exibições culturais, musicais, televisivas e festivais, constituindo um espaço híbrido, pois acolhem outras funções ao seu programa, como restaurantes, museus e lojas. Sua forma espetacular, icônica, e a reprodução de sua imagem, potencializada pela audiência televisiva internacional dos megaeventos, funcionam como um signo que representa e amplifica a imagem do lugar anfitrião, muito embora sua condição espacial não corresponda à totalidade da cidade, mas apenas um fragmento. O efeito da imagem é global, mas o impacto é local. 
A Allianz Arena (Munich, Alemanha), por exemplo, da dupla de arquitetos suíços Herzog e de Meuron, construída para sediar a abertura da Copa de 2006, apela sob vários aspectos para o caráter espetacular, presente na valorização da superfície que envolve o edifício e nos efeitos de iluminação.

O estádio foi a edificação esportiva mais midiática já construída para um grande evento (até ser superado pela própria dupla, poucos anos depois, em Pequim), com sua imagem surpreendente - como um enorme pneumático iluminado em azul, vermelho ou branco -, divulgada sem cessar nos quatro cantos do globo (Arantes, 2012, p. 100).

Esta preocupação com a forma, entendida aqui como figura, epiderme, superfície, e não como estrutura interna do edifício, revela uma atitude arquitetônica que remonta às origens do pós-modernismo arquitetônico e presente nas convicções de Venturi relativas ao "galpão decorado", em que as relações entre forma, função e estrutura se tornam autônomas. Na Allianz Arena, a forma espetacular tem primazia sobre a solução funcional e estrutural, que são meros fatos operacionais e técnicos.

Arantes (2011) afirma que a Nova China passou a compor o imaginário internacional de forma mais intensa a partir da realização do megaevento das Olimpíadas de Pequim de 2008, encarado como um grande espetáculo global.

Tais espetáculos são hoje parte da paisagem, cuja rotina - nada mais monótona do que a imensa "coleção de mercadorias" a que o mundo, agora único, finalmente se reduziu - são chamados a quebrar e afinal celebrar. Na forma de um drama - o que não falta são palcos, cenários e sobretudo a encenação do envolvimento da massa consumidora como o público desse teatro na escala do globo - algo como uma cerimônia ritual de apaziguamento e controle por meio da inoculação de doses colossais de aura e carisma na vida ordinária de multidóes anestesiadas pelo sentimento da própria insignificância (Arantes, 2011, p. 75).

Alguns edifícios voltados para o espetáculo olímpico foram construídos em Pequim ao longo de um eixo monumental com características espetaculares, dentre eles: o famoso estádio olímpico, conhecido popularmente como Ninho de Pássaro (Figura 7), dos arquitetos Herzog e de Meuron, onde a estrutura complexa constitui em si o ornamento e a imagem do edifício e o centro aquático (Cubo d'Água - Figura 8), do escritório australiano PTW, que possui uma inspiração figurativa e teve grande repercussão mundial, como um espetáculo cenográfico. As obras de infrestrutura e intervenções urbanas monumentais também compõem o rol do espetáculo criado para acolher os Jogos Olímpicos, como o Aeroporto Internacional de Pequim, do arquiteto Norman Foster, e o grande prolongamento do eixo imperial até o Parque Olímpico.

As experiências arquitetônicas na Copa da Alemanha de 2006 e nas Olimpíadas de Pequim em 2008 foram paradigmáticas no reforço da criação de uma arquitetura espetacular nos megaeventos esportivos seguintes, sendo, inclusive, uma estratégia presente nas candidaturas dos lugares para sediá-los, com propostas arquitetônicas inimagináveis como forma de potencializar as chances de vencer o pleito de sediar o megaevento. 

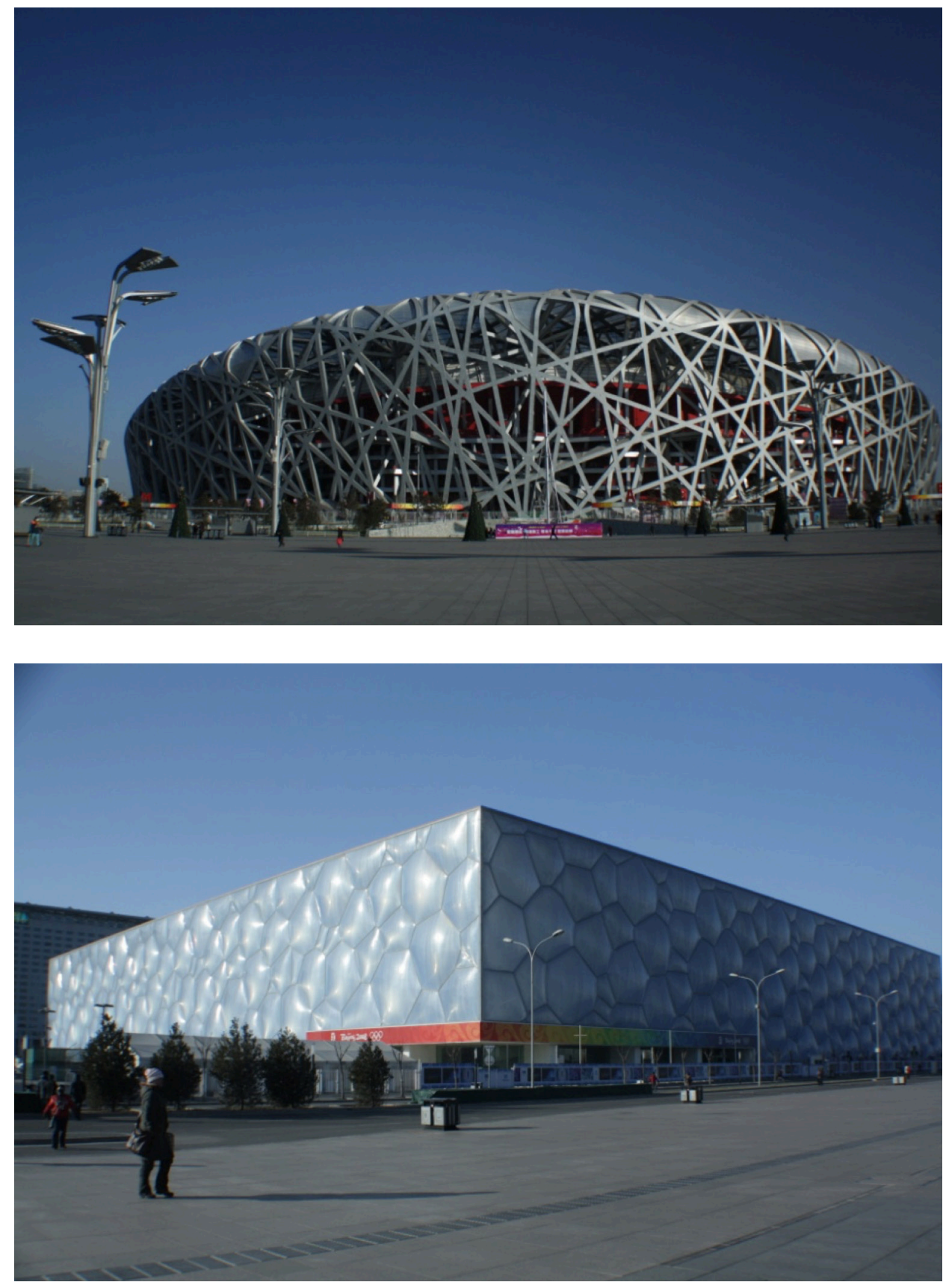

Figura 7: Ninho de Pássaro, dos arquitetos Herzog e de Meuron. Fonte: Thiago Allis.

Figura 8: Centro Aquático (Cubo d'Água), do escritório australiano PTW. Fonte: Thiago Allis. 
Figura 9: Museu do Amanhã (2016), do arquiteto Santiago Calatrava. Fonte: Foto do autor.
As arenas construídas para as Copas do Mundo da África do Sul (2010) e do Brasil (2014) exemplificam de alguma forma a reprodução de uma arquitetura espetacular, muito embora, em virtude das preexistências socioespaciais desiguais e contraditórias da realidade destes países e inserções periféricas na lógica dos fluxos econômicos globais, a construção destas arenas esportivas, para além e mais grave que sua condição estética, exacerbou os processos de fragmentação e segregação urbana, além dos problemas criados em relação à gestão e manutenção destes estádios, sobretudo nas cidades em que a magnitude da obra está em descompasso com as práticas esportivas e futebolísticas, como aconteceu na África do Sul e em algumas cidades brasileiras nas quais o futebol não tem grande vitalidade, como Manaus, Cuiabá e até mesmo Brasília.

As infraestruturas esportivas para a realização das Olimpíadas de Londres (2012) apontaram para a criação de estruturas transitórias e efêmeras, ou mesmo com possibilidade de flexibilização para outros usos, o que demonstra uma certa lucidez em relação à produção da arquitetura para os megaeventos.

Esta atitude inspirou o processo de construção de algumas estruturas para as Olimpíadas do Rio (2016), muito embora prevaleça o apelo a uma arquitetura espetacular, inclusive em uma orquestração, como em Pequim, de um conjunto de intervenções e projetos urbanos estratégicos para reestruturar a cidade e reinventar sua imagem, intervindo e gentrificando áreas consolidadas, com o projeto Porto Maravilha e o Museu do Amanhã (Figura 9), do arquiteto Santiago Calatrava, na zona portuária, e a criação de centralidades e frentes de expansão imobiliária com o projeto da Vila Olímpica.

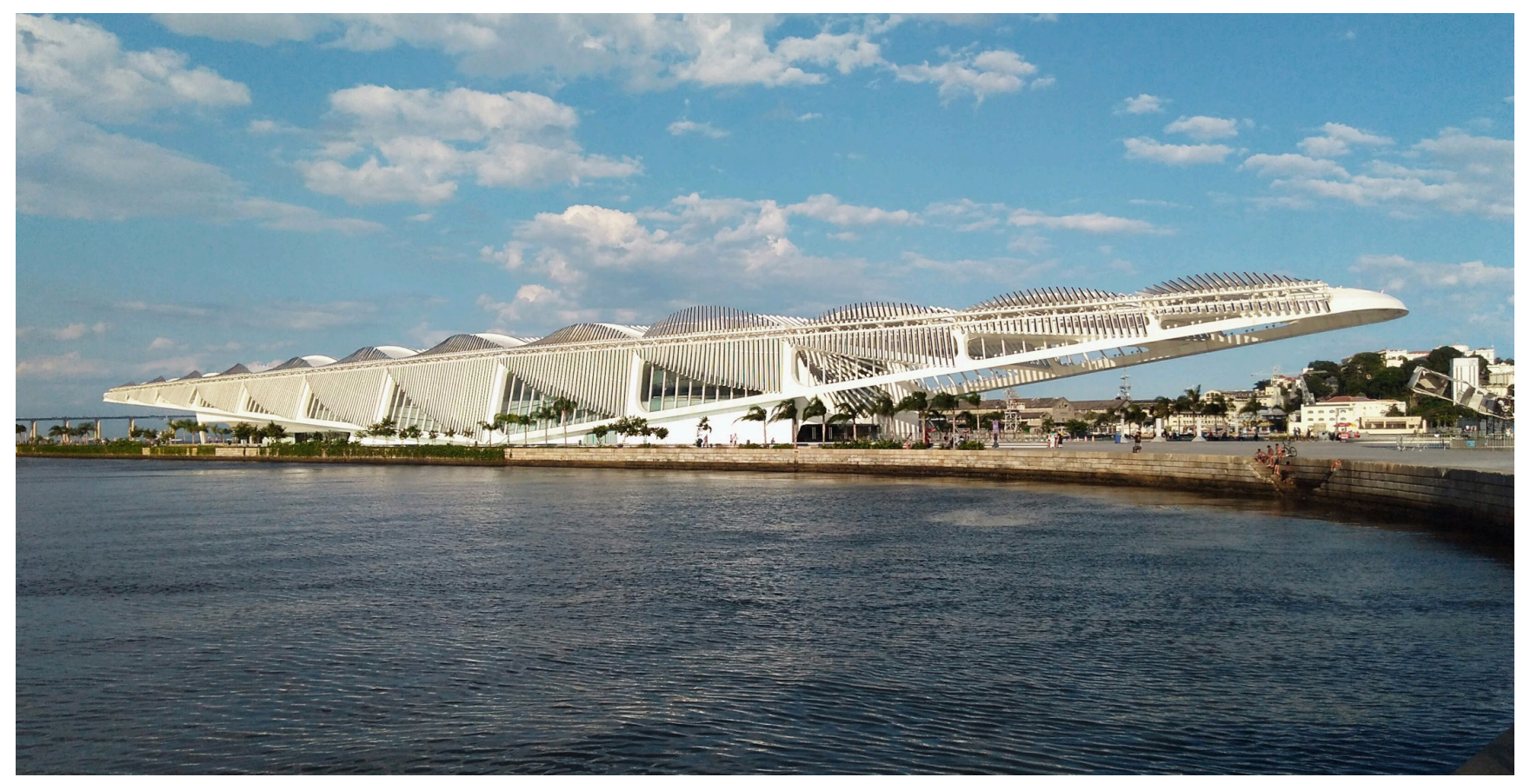

risco. 17_3 


\section{Considerações finais}

Como síntese, é possível perceber valores arquétipos na arquitetura voltada para o espetáculo e no caráter espetacular do edifício, que desde tempos remotos são utilizados para seduzir e estimular os sentidos e o prazer, frequentemente direcionados e desviados para outros propósitos.

Para além do potencial de alienação da arquitetura do espetáculo, por meio do edifícioevento, é importante denunciar o fato de que esta arquitetura do espetáculo em geral, e especificamente no Brasil, se insere em uma política urbana excludente, que planeja e intervém na cidade de forma seletiva, que estimula a valorização imobiliária e a especulação fundiária, que reforça o processo de privatização do espaço público, que concede investimentos e financiamentos públicos que beneficiam empresas envolvidas na construção destes edifícios (além das infraestruturas) e posteriormente em sua gestão, que estão a serviço da reprodução do capital internacional e, o pior, vulneráveis à corrupção, em escala nacional a global.

Ao mesmo tempo que o espetáculo tem potencial de despolitizar, ele também pode criar condições de insatisfação e resistência aos interesses hegemônicos velados pela estética e pela imagem da arquitetura. Os arquitetos podem contribuir para este processo na medida em que criem formas arquitetônicas que estejam articuladas e conscientes de suas complexas implicações sociais (econômicas, políticas e simbólicas), para uma transformação ampla e inclusiva. A ética e a estética são desejáveis na produção da arquitetura por meio de uma permanente atitude crítica nos âmbitos do projeto e da produção intelectual, pela reivindicação do redimensionamento da função do arquiteto na sociedade e pela garantia do direito à cidade, para além do espetáculo.

\section{Referências bibliográficas}

ARANTES, O. B. F. Chai-Na. São Paulo: Edusp, 2011

ARANTES, P. F. Arquitetura na era digital-financeira: desenho, canteiro e renda da forma. São Paulo: Editora 34, 2012.

BENÉVOLO, L. A história da cidade. São Paulo: Perspectiva, 1997.

BENJAMIN, W. Walter Benjamin: Sociologia. 2.ed. Trad. e org. por Flávio Kothe. São Paulo: Ática, 1991.

BROUDEHOUX, A. M. Imagens do poder: arquiteturas do espetáculo integrado na Olimpíada de Pequim. Novos estudos-CEBRAP, n. 89, p. 39-56, 2011.

BUENO, F. S. Grande dicionário etimológico-prosódico da língua portuguesa. São Paulo: Saraiva, 1961

CASTELLS, M. A questão urbana. São Paulo: Paz e Terra, 2009.

CASTELO, R.M. A Guisa de Apresentação. In: BRAGA, B.M.; RIBEIRO, I.L. e; LIMA, L.S. (Orgs). Fórum Jovens Arquitetos Latino-Americanos - Inserções numa realidade periférica. Fortaleza: Expressão Gráfica e Editora, 2013.

DEBORD, G. A sociedade do espetáculo. Rio de Janeiro: Contraponto, 1997. 
DE LIMA, M. A. et al. Olimpíadas modernas: a história de uma tradição inventada. Pensar a Prática, v. 12, n. 1, abr. 2009. Disponível em: <https://revistas.ufg.emnuvens.com.br/fef/ article/view/5874/4758>. Acesso em: 17 maio 2016.

HARVEY, D. Paris, capital da modernidade. São Paulo: Boitempo, 2015.

JAMESON, F. Pós-modernismo: a lógica cultural do capitalismo tardio. São Paulo: Ática, 1996.

LLOSA, M. V. A civilização do espetáculo: uma radiografia do nosso tempo e da nossa cultura. Rio de Janeiro: Objetiva, 2013

MONNIER, G. O edifício, instrumento do evento: uma problemática. Revista CPC, São Paulo, n. 7, p. 7-19, nov. 2008/abr. 2009.

MONTANER, J. M. As formas do século XX. Barcelona: Gustavo Gili, 2002.

PAIVA, R. A. Os ícones urbanos e arquitetônicos. In: VARGAS, H. C.; PAIVA, R. A. (Org.). Turismo, arquitetura e cidade. Barueri: Manole, 2016. p. 289-314.

SKLAIR, L. Iconic architecture and capitalist globalization. City, v. 10, n. 1, p. 21-47, 2006.

Iconic architecture and the culture-ideology of consumerism. Theory. Culture \& Society, n. 27, p.135-159, 2010.

TUROLLA, Frederico A. A economia da COPA. Disponível em: <www.abdibcopa2014.org.br>. Acessado em: 1 nov. 2009.

URSPRUNG, P. Toward a critical realism? Herzog \& de Meuron and the architecture of spectacle. There, Journal of Architecture and Landscape, A Publication of the College of Architecture and Landscape Architecture, University of Minnesota, "Importing Spectacle", n. 1, p. 7481, 2005.

ZUKIN, S. Aprendendo com Disney World. Espaço \& Debates, São Paulo, v.23, n.43-44, p.1127, 2003. 